\title{
Evaluation of behavioral states among morning and evening active healthy individuals
}

\section{M.P. Hidalgo ${ }^{1}$, \\ A. Camozzato ${ }^{1}$, L. Cardoso ${ }^{1}$, \\ C. Preussler ${ }^{1}$, C.E. Nunes ${ }^{1}$, \\ R. Tavares ${ }^{1}$, M.S. Posser ${ }^{1}$ and M.L.F. Chaves ${ }^{1,2}$}

\author{
${ }^{1}$ Curso de Pós-Graduação de Medicina Interna, and \\ ${ }^{2}$ Serviço de Neurologia, Programa de Ciências do Comportamento, \\ Faculdade de Medicina, Universidade Federal do Rio Grande do Sul, \\ Porto Alegre, RS, Brasil
}

\section{Correspondence \\ M.L.F. Chaves \\ Serviço de Neurologia \\ Hospital de Clínicas de Porto Alegre \\ R. Ramiro Barcelos, 2350, Sala 2040 \\ 90035-003 Porto Alegre, RS \\ Brasil \\ Fax: +55-51-3311-4684 \\ E-mail: mchaves@vanet.com.br}

Received November 26, 2001 Accepted April 30, 2002

\section{Abstract}

The Horne-Östberg questionnaire partly covers some factors that may be important determinants of peak time and characterize patterns of behavior. We conducted a study for the evaluation of self-reported behavioral states (hunger sensation, availability for study, physical exercise, solving daily problems, and time preferences) as expressions of underlying cyclic activity. Three hundred and eighteen community subjects without history of medical, psychiatric, or sleep disorders were evaluated in a cross-sectional design. A self-report about daily highest level of activity was used to categorize individuals into morning, evening, and indifferently active. Time-related behavioral states were evaluated with 23 visual analog questions. The responses to most analogic questions were significantly different between morning and evening active subjects. Logistic regression analysis identified a group of behaviors more strongly associated with the self-reported activity pattern (common wake up time, highest subjective fatigue, as well as wake up, bedtime, exercise and study preferences). These findings suggested that the patterns of activity presented by normal adults were related to specific common behavioral characteristics that may contribute to peak time.
Rhythmicity is part of our life. In the last decade there has been increasing interest in research focusing on the interplay between the human circadian timing system and behavioral patterns in health and illness. Of particular interest in this area of inquiry is the overlay of what has been termed chronotype. What this refers to is the propensity of biological rhythms to express themselves in certain patterns of behavior. Commonly, people showing these patterns have received names such as 'owl' (evening chronotype) or 'lark' (morning chronotype) (1), but many people

\section{Key words}

- Chronobiology

- Morningness

- Eveningness

- Circadian rhythm

- Behavior

- Human are neither strongly morning nor evening type. If illness represents a change in the way a person's body functions within a given environment, then it is reasonable to believe that an "owl's" symptom presentation may vary significantly from the patterns of a "lark" who becomes ill. The interplay between the body's timing system and the thousands of other psychobiological rhythmic functions occurring everyday and within every human being is referred to as chronobiology (2).

In the late 70's, Horne and Östberg (3) developed a questionnaire for the identifica- 
tion of Morning, Evening and Indifferent types based on their circadian peak times identified from the smoothed temperature curves of each subject. Morning types had a significantly earlier peak time than Evening types and tended to have a higher daytime temperature and lower post-peak temperature. The Indifferent type had temperatures between those of the other groups. No significant differences in sleep lengths were found between the three types; however, Morning types retired and arose significantly earlier than Evening types. The authors concluded that, although sleep habits were an important determinant of peak time, there were other contributory factors, which appeared to be partly covered by the questionnaire and suggested further investigations.

Because the Horne-Östberg questionnaire for Morningness/Eveningness (MEQ) partly covers other contributory factors that may be important determinants of peak time, we undertook a study to evaluate other behavioral states as expressions of underlying cyclic activity involving physiological systems. For this initial investigation we selected selfreported daily patterns of activity to classify subjects $(4,5)$ and not the MEQ in order to avoid the influence of concepts on the behavioral items under study. The validity of the self-report in relation to the MEQ is presently under investigation. The MEQ has been already studied in Brazilian samples $(6,7)$.

This cross-sectional study was carried out on normal volunteers after approval by the Ethics Committee for Medical Research of the University Hospital. Participants were recruited from the university student population and the general public and each signed a consent form. Exclusion criteria included sleep disorders and history of medical and psychiatric diagnosis. Of the 318 individuals who composed the sample, 182 were males; age ranged from 18 to 34 years (mean $\pm \mathrm{SD}$, $21.34 \pm 2.80$ ) and schooling from 11 to 22 years $(12.82 \pm 1.89)$. Subjects were classified into three groups, i.e., morning active, evening active and indifferently active according to their self-perceptions. A questionnaire composed of 23 self-report visual analog questions was answered by the participants $(10-\mathrm{cm}$ line on which the subject marked the point that best described his/her perception of time or feelings). For the items related to perceptions, higher values were assigned to the 'very easy' side of the analogic line.

All variables were submitted to a pegboard test (normal probability plot) before parametric analysis (ANOVA plus Tukey test, MANOVA, or Student $t$-test) by the SPSS/PC Plus software. Categorical variables were analyzed by chi-square tests. A logistic model was developed for regression analysis with the questions that reached statistical difference by MANOVA (8) for the identification of those more strongly associated with the dependent variable, the selfreported pattern of activity.

Of the 318 subjects interviewed, 159 selfreported as evening (101 males/58 females), 83 as morning ( 32 males/51 females) and 76 as indifferently active ( 49 males $/ 26$ females). More women reported to be morning active than men did $\left(\chi^{2}=16.42\right.$ and $\left.\mathrm{P}=0.003\right)$. Mean $( \pm$ SD) age was $21.46 \pm 2.97$ years for the evening active group, $21.57 \pm 2.86$ for the morning group, and $20.84 \pm 2.28$ for the indifferent group $(\mathrm{F}=1.633 ; \mathrm{P}=0.1286$, one-way ANOVA). Schooling did not differ among groups $(\mathrm{F}=2.064 ; \mathrm{P}=0.197$, oneway ANOVA), with a mean number of years $( \pm \mathrm{SD})$ of $12.84 \pm 2.01$ for the evening group, $13.08 \pm 1.92$ for the morning group and $12.48 \pm 1.53$ for the indifferent group.

The morning and evening active individuals presented statistically significant differences for most visual analog questions, controlled for sex by MANOVA (Table 1). Questions without significant differences were common wake up schedule (last year), subjective fatigue after wake up, availability for exercise in the evening, for study late in the afternoon $(5: 00 \mathrm{pm})$ and for solving daily 
problems after 10:00 pm, and hunger sensation after 5:00 pm.

Logistic regression analysis showed that difficulty to wake up at the commonest wake up schedule during the last year $(\mathrm{B}=0.19$; Wald $=4.99 ; \mathrm{P}=0.0255)$, schedule of high est subjective fatigue $(\mathrm{B}=0.25$; Wald $=$ 8.95; $\mathrm{P}=0.0028)$, wake up preference $(\mathrm{B}=$ -1.19; Wald $=10.71 ; \mathrm{P}=0.001)$, bedtime preference $(\mathrm{B}=-0.11 ;$ Wald $=3.84 ; \mathrm{P}=$ 0.05 ), schedules of preference for exercise and study $(\mathrm{B}=-0.26 ;$ Wald $=5.84 ; \mathrm{P}=0.02$, and $\mathrm{B}=-0.26$; Wald $=6.59 ; \mathrm{P}=0.01$ ) were the aspects with highest coefficients. The group of questions kept in the model presented an odds ratio of 23.41 (95\% confidence limit 11.10-50.10) and explained $83.88 \%$ of the outcome (self-reported morning and evening active).

Some variables were strongly related to patterns of activity similar to those observed in morning and evening types according to

Table 1. Responses to the questionnaire composed of 23 self-report visual analog questions.

\begin{tabular}{|c|c|c|c|c|}
\hline Questions & $\begin{array}{l}\text { Evening } \\
\text { active } \\
(\mathrm{N}=159)\end{array}$ & $\begin{array}{l}\text { Morning } \\
\text { active } \\
(\mathrm{N}=83)\end{array}$ & $\begin{array}{l}\text { Indifferently } \\
\text { active } \\
(\mathrm{N}=76)\end{array}$ & $P$ \\
\hline 1 - Common wake up schedule (last year) & $2.90 \pm 0.54$ & $2.75 \pm 0.41$ & $2.81 \pm 0.42$ & 0.071 \\
\hline 2 - How difficult is it to wake up at the time indicated in question $1 ?$ & $4.08 \pm 2.16$ & $6.16 \pm 2.37$ & $5.35 \pm 2.25$ & 0.000 \\
\hline 3 - How difficult is it to get out of bed? & $4.22 \pm 2.57$ & $6.06 \pm 2.55$ & $5.26 \pm 2.62$ & 0.000 \\
\hline 4 - How tired do you feel as soon as you wake up? & $4.42 \pm 2.31$ & $4.09 \pm 2.35$ & $4.35 \pm 1.75$ & 0.852 \\
\hline 5 - How hungry are you in the morning? & $3.80 \pm 2.50$ & $4.83 \pm 2.52$ & $4.52 \pm 2.38$ & 0.005 \\
\hline 6 - How do you feel immediately after waking up? & $4.75 \pm 2.27$ & $6.22 \pm 2.29$ & $6.14 \pm 2.20$ & 0.000 \\
\hline 7 - How do you feel about exercising in the moming? & $4.99 \pm 2.70$ & $6.83 \pm 2.31$ & $6.29 \pm 2.41$ & 0.000 \\
\hline $\begin{array}{l}8 \text { - How ready are you to study in the moming compared to other periods of } \\
\text { the day? }\end{array}$ & $5.27 \pm 2.58$ & $7.69 \pm 1.98$ & $6.96 \pm 2.43$ & 0.000 \\
\hline $\begin{array}{l}9 \text { - How ready are you to solve daily problems as soon as you wake up } \\
\text { in the moming? }\end{array}$ & $4.88 \pm 2.39$ & $7.03 \pm 2.09$ & $6.42 \pm 2.44$ & 0.000 \\
\hline 10 - How do you feel about exercising in the evening? & $6.50 \pm 2.48$ & $5.92 \pm 2.43$ & $6.68 \pm 2.50$ & 0.117 \\
\hline 11 - How do you feel about studying late in the aftemoon (5:00 pm)? & $5.93 \pm 2.67$ & $5.56 \pm 2.49$ & $5.54 \pm 2.45$ & 0.426 \\
\hline 12 - How hungry do you feel after 5:00 pm? & $3.53 \pm 2.44$ & $4.16 \pm 2.77$ & $3.45 \pm 2.40$ & 0.120 \\
\hline 13 - How tired are you after 5:00 pm? & $5.11 \pm 2.24$ & $4.78 \pm 1.96$ & $5.53 \pm 2.06$ & 0.087 \\
\hline 14 - How ready are you to solve daily problems after $10: 00 \mathrm{pm} ?$ & $5.47 \pm 2.54$ & $4.69 \pm 2.78$ & $4.90 \pm 2.76$ & 0.066 \\
\hline $\begin{array}{l}15 \text { - During the last year, at what time did you fall asleep more } \\
\text { frequently?* }\end{array}$ & $12.68 \pm 6.2$ & $10.44 \pm 4.10$ & $12.12 \pm 6.03$ & 0.016 \\
\hline $\begin{array}{l}16 \text { - At what time was your highest level of subjective fatigue, } \\
\text { considering the last year? }\end{array}$ & $6.02 \pm 2.91$ & $8.34 \pm 1.93$ & $7.67 \pm 2.30$ & 0.000 \\
\hline 17 - How is your general disposition after 11:00 pm? & $4.88 \pm 2.61$ & $4.09 \pm 3.19$ & $3.65 \pm 2.83$ & 0.005 \\
\hline $\begin{array}{l}18 \text { - If you were free of schedules and might choose your time to wake up, } \\
\text { taking into account exclusively your natural rhythm, what time would it be? }\end{array}$ & $4.23 \pm 0.73$ & $3.52 \pm 0.53$ & $3.84 \pm 0.59$ & 0.000 \\
\hline $\begin{array}{l}19 \text { - If you were free to choose your bedtime, taking into account } \\
\text { exclusively your natural rhythm, what time would it be?* }\end{array}$ & $3.78 \pm 7.09$ & $9.42 \pm 2.45$ & $11.27 \pm 5.29$ & 0.000 \\
\hline $\begin{array}{l}20 \text { - If you were free to choose your exercise schedule, taking into } \\
\text { account exclusively your natural mythm, what time would you choose? }\end{array}$ & $6.71 \pm 1.55$ & $5.21 \pm 1.80$ & $6.16 \pm 1.69$ & 0.000 \\
\hline $\begin{array}{l}21 \text { - If you were free to choose your study schedule, taking into } \\
\text { account exclusively your natural rhythm, what time would you choose? }\end{array}$ & $6.14 \pm 2.28$ & $4.29 \pm 1.42$ & $5.41 \pm 1.95$ & 0.000 \\
\hline $\begin{array}{l}22 \text { - If you were free to choose a time to solve your daily problems, taking into } \\
\text { account exclusively your natural rhythm, what time would you choose? }\end{array}$ & $6.18 \pm 1.87$ & $4.72 \pm 1.32$ & $5.33 \pm 1.72$ & 0.000 \\
\hline $\begin{array}{l}23 \text { - If you were free of schedules at what time would you have } \\
\text { your main meal? }\end{array}$ & $5.91 \pm 1.50$ & $5.57 \pm 1.35$ & $5.46 \pm 1.22$ & 0.037 \\
\hline
\end{tabular}

Responses reported as mean \pm SD for the score on a 10-cm line on which the subject marked the point that best described his/her perception of time or feelings.

MANOVA multivariate procedure, sex controlled. The $P$ value refers to the statistical significance for the comparisons of the 3 groups.

*Questions adjusted to properly represent schedules after 12:00 pm. 
the Horne-Östberg questionnaire. Although most of the variables showed differences between the self-reported morning and evening active groups, only those related to period of the day of higher subjective fatigue, wake up, bedtime, exercise and study preferences were effectively associated with the way these normal community individuals classified themselves. A subject was more likely to report him- or herself as a morning active person when experiencing less difficulty in waking up at the common wake up schedule, higher subjective fatigue late in the evening, earlier wake up, bedtime, exercise and study schedule preferences. Morningness has been associated with earlier wake up time and bedtime, less time in bed, better alertness at wake up time, less time spent asleep, decreased REM activity, shorter REM stage, longer stage I and fewer minutes of stage II (9). Ease in carrying out activities early in the morning, with a more pleasurable emotional state (10) and clear prefer- ence to fall asleep early at night characterize morningness (1). On the other hand, a higher probability of eveningness was conferred by difficulty to wake up at the common wake up schedule, highest level of tiredness in the morning, and later wake up, bedtime, exercise and study schedule preferences. Easiness to carry out activities late at night, clear preference to wake up late in the morning during weekends, and better wakefulness in the evening have been shown to characterize the evening type $(1,10)$.

Within-group comparisons of hunger sensation, availability for study, physical exercise, general disposition, solving daily problems, subjective fatigue, common wake up and bedtime schedules and preference are displayed in Table 2. A significant difference between frequent and preferred wake up time was observed between groups. Morning and evening active groups woke up significantly earlier than they wished during the last year (around 7:00 and 10:00 am, respec-

Table 2. Comparison of time behaviors within moming and evening active individuals.

\begin{tabular}{|c|c|c|c|c|c|c|c|c|}
\hline \multirow[t]{2}{*}{ Variable } & \multicolumn{4}{|c|}{ Evening active } & \multicolumn{4}{|c|}{ Morning active } \\
\hline & $\begin{array}{l}\text { Mean } \pm \text { SD } \\
\text { in the morming }\end{array}$ & $\begin{array}{c}\text { Mean } \pm \text { SD } \\
\text { in the aftemoon }\end{array}$ & $\mathrm{t}$ & $\mathrm{P}$ & $\begin{array}{l}\text { Mean } \pm \text { SD } \\
\text { in the moming }\end{array}$ & $\begin{array}{c}\text { Mean } \pm \text { SD } \\
\text { in the afternoon }\end{array}$ & $\mathrm{t}$ & $P$ \\
\hline Hunger sensation & $3.80 \pm 2.50$ & $3.53 \pm 2.44$ & 0.94 & 0.349 & $4.83 \pm 2.52$ & $4.16 \pm 2.77$ & 1.59 & 0.116 \\
\hline Study & $5.27 \pm 2.58$ & $5.93 \pm 2.67$ & -2.01 & 0.047 & $7.69 \pm 1.98$ & $5.56 \pm 2.49$ & 5.58 & 0.000 \\
\hline Fatigue & $4.42 \pm 2.31$ & $3.63 \pm 2.14$ & 1.63 & 0.113 & $4.09 \pm 2.35$ & $5.04 \pm 2.05$ & -1.51 & 0.144 \\
\hline Exercise & $4.99 \pm 2.70$ & $6.50 \pm 2.48$ & -5.29 & 0.000 & $6.83 \pm 2.31$ & $5.92 \pm 2.44$ & 2.40 & 0.019 \\
\hline Problem solving & $4.88 \pm 2.39$ & $5.47 \pm 2.54$ & -1.95 & 0.053 & $7.03 \pm 2.09$ & $4.69 \pm 2.78$ & 5.71 & 0.000 \\
\hline \multirow[t]{2}{*}{ General disposition } & $4.75 \pm 2.27$ & $4.88 \pm 2.61$ & -0.48 & 0.632 & $6.22 \pm 2.29$ & $4.09 \pm 2.29$ & 4.86 & 0.000 \\
\hline & $\begin{array}{c}\text { Mean } \pm S D \\
\text { of frequent } \\
\text { time }^{a}\end{array}$ & $\begin{array}{l}\text { Mean } \pm S D \\
\text { of preferred } \\
\text { time }\end{array}$ & $\mathrm{t}$ & $\mathrm{P}$ & $\begin{array}{c}\text { Mean } \pm S D \\
\text { of frequent } \\
\text { time }^{a}\end{array}$ & $\begin{array}{l}\text { Mean } \pm S D \\
\text { of preferred } \\
\text { time }\end{array}$ & $\mathrm{t}$ & $P$ \\
\hline Wake up time* & $\begin{array}{c}8 \mathrm{~h} 27 \mathrm{~min} \pm \\
32 \min \\
(2.90 \pm 0.54)\end{array}$ & $\begin{array}{c}10 \text { h } 9 \min \pm \\
44 \min \\
(4.23 \pm 0.73)\end{array}$ & -18.81 & 0.000 & $\begin{array}{c}6 \mathrm{~h} 36 \min \pm \\
24 \min \\
(2.75 \pm 0.41)\end{array}$ & $\begin{array}{c}6 \text { h } 58 \min \pm \\
32 \min \\
(3.52 \pm 0.53)\end{array}$ & -11.85 & 0.000 \\
\hline Bedtime* & $\begin{array}{c}23 \text { h } 24 \min \pm \\
11 \text { h } 16 \text { min } \\
(12.68 \pm 6.3)\end{array}$ & $\begin{array}{c}1 \mathrm{~h} 26 \mathrm{~min} \pm \\
12 \mathrm{~h} 5 \mathrm{~min} \\
(13.78 \pm 7.1)\end{array}$ & -1.78 & 0.078 & $\begin{array}{l}20 \text { h } 53 \mathrm{~min} \\
\pm 7 \text { h } 6 \mathrm{~min} \\
(10.44 \pm 4.1)\end{array}$ & $\begin{array}{l}18 \text { h } 50 \text { min } \pm \\
3 \text { h } 27 \text { min } \\
(9.42 \pm 2.45)\end{array}$ & 2.25 & 0.026 \\
\hline
\end{tabular}

aWeekdays.

*Scores from the visual analog line transformed to time schedules.

Student t-test for dependent samples. 
tively). Nonetheless, a significant difference between frequent and preferred bedtime was seen only among the morning subjects. The evening individuals showed similar frequent and preferred bedtimes, although the schedule of preference was later (1:26 am) than the frequent one (11:24 pm).

Morning and evening active individuals did not present different perceptions of hunger sensation between morning and afternoon (Table 1); however, hunger in the morning was significantly different between groups (Table 2). Individual hunger sensation time-qualified scores (orexigram) may be used to investigate whether or not a single subject is synchronized for sleep-wake cycle, meal time schedule and socio-occupational routines (11).

For evening subjects, availability for study and for physical exercise increased from the morning to the evening, while general disposition was similar. They also tended to be more available to solve daily problems in the afternoon than in the morning. In turn, morning individuals presented a decrease from the morning to afternoon or evening in the availability for study, for exercise, for solving problems, and general disposition. Morning and afternoon subjective fatigue was similar within both groups.

The relations between physical exercise and chronotype are still controversial, since workout performance is a result of many variables, including day shift (12-15). A previous study (16) did not find differences in responses to exercise between morning and evening types; however, another investigation demonstrated that evening individuals had a higher energetic arousal in the evening than in the morning (17). The influence of exercise on melatonin secretion supports the hypothesis that physical activity may be a significant zeitgeber ("time-giver") in hu- mans (18). Optimal time of day for exercise is determined not just by endogenous rhythms but also by the nature and intensity of exercise, the population concerned, environmental conditions, and individual phase types. The existence of self-sustaining rhythms should be recognized by athletic practitioners, sports scientists concerned with experimental work and fitness testing, sports injury specialists, and sports organizers concerned with the travel plans of athletes (12).

Recognizing that clinicians and psychiatrists at both the generalist and the advanced practice levels have a strong need for tools permitting quick recognition of patterns of behavior, it stands to reason that a vision that incorporates notions of the body's clock becomes essential. Diurnal variation of mood can be observed in healthy individuals and differs between morning-type and eveningtype subjects (19). Environmental factors impinging on circadian rhythms include light, heat, activity and eating patterns, and social activities. Endogenous rhythms are desynchronized when perturbed by night shift work, time-zone transitions, and by most disorders affecting sleep. Coping with desynchronosis involves behavioral, dietary, or pharmacological treatments. The present findings suggest that the interplay between the body's timing system and rhythmic psychobiological functions such as hunger, availability for exercise, study, solving daily problems, etc., occurring everyday and within every human being characterizes specific patterns of behavior. These patterns may present predictive values, risk for or protection from psychiatric disorders and may affect pharmacotherapy, similar to what has been observed for hypertension and other medical conditions (20). Further investigations are needed to explore the role of chronotype in psychiatric symptoms and disorders. 


\section{References}

1. Sexton-Radex K \& Harris D (1992). Morningness versus eveningness arousal pattems in young adults. Perceptual and Motor Skills, 74: 115-119.

2. Aschoff J (1998). Circadian parameters as individual characteristics. J ournal of Biological Rhythms, 13: 123-131.

3. Horne JÁ \& Östberg O (1976). A selfassessment questionnaire to determine morningness-eveningness in human circadian rhythms. International J ournal of Chronobiology, 4: 97-110.

4. Duffy J F, Dijk DJ, Hall EF \& Czeisler CA (1999). Relationship of endogenous circadian melatonin and temperature rhythms to self-reported preference for morning or evening activity in young and older people. J ournal of Investigative Medicine, 47: 141-150.

5. Froberg J E (1977). Twenty-four-hour pattems in human performance, subjective and physiological variables and differences between morning and evening active subjects. Biological Psychology, 5: 119-134.

6. Benedito-Silva AA, Menna-Barreto $L$, Marques N \& Tenreiro S (1990). A selfassessment questionnaire for the determination of morningness-eveningness types in Brazil. Progress in Clinical and Biological Research, 341B: 89-98.

7. Andrade MM, Benedito-Silva AA \& Menna-
Barreto L (1992). Correlations between morningness-eveningness character, sleep habits and temperature rhythm in adolescents. Brazilian J ournal of Medical and Biological Research, 25: 835-839.

8. Fleiss J L (1986). The Design and Analysis of Clinical Experiments. J ohn Wiley \& Sons, New York, NY, USA.

9. Carrier J , Monk TH, Buysse DJ \& Kupfer DJ (1997). Sleep and morningnesseveningness in the 'middle' years of life (20-59 y). J oumal of Sleep Research, 6: 230-237.

10. Chebat J C, Dubé L \& Marquis M (1997). Individual differences in circadian variations of consumers' emotional state. Perceptual and Motor Skills, 84: 1075-1086.

11. Cugini $P$, Camillieri G, Alessio L, Cristina G, De Rosa R \& Petrangeli CM (2000). Daily hunger sensation monitoring as a tool for investigating human circadian synchronization. Eating and Weight Disorders, 5: 24-30.

12. Reilly $T$ (1990). Human circadian rhythms and exercise. Critical Reviews in Biomedical Engineering, 18: 165-180.

13. O'Connor PJ \& Davis J C (1992). Psychobiologic responses to exercise at different times of day. Medicine and Science in Sports and Exercise, 24: 714-719.

14. Trine MR \& Morgan WP (1995). Influence of time of day on psychological responses to exercise. A review. Sports Medicine, 20: 328-337.

15. Deschenes MR, Sharma J V, Brittingham KT, Casa DJ , Armstrong LE \& Maresh CM (1998). Chronobiological effects on exercise performance and selected physiological responses. European J ournal of Applied Physiology, 77: 249-256.

16. Hill DW, Cureton KJ, Collins MA \& Grisham SC (1988). Diumal variation in responses to exercise of "morning types" and "evening types". Joumal of Sports Medicine and Physical Fitness, 28: 213219.

17. Winget CM, DeRoshia CW \& Holley DC (1985). Circadian rhythms and athletic performance. Medicine and Science in Sports and Exercise, 17: 498-516.

18. Atkinson $G \&$ Reilly $T$ (1996). Circadian variation in sport performance. Sports Medicine, 21: 292-312.

19. Kerkhof GA (1998). The 24-hour variation of mood differs between morning- and evening-type individuals. Perceptual and Motor Skills, 86: 264-266.

20. Smolensky $\mathrm{MH} \&$ Portaluppi $\mathrm{F}$ (1999). Chronopharmacology and chronotherapy of cardiovascular medications: relevance to prevention and treatment of coronary heart disease. American Heart J ournal, 137: S14-S24. 